\title{
Effect of Cystamine on Blood Pressure and Vascular Characteristics in Spontaneously Hypertensive Rats
}

\author{
M. Engholm ${ }^{a} \quad$ A. Eftekhari ${ }^{a} \quad$ G. Chwatko ${ }^{b} \quad$ E. Bald ${ }^{b}$ M.J. Mulvany ${ }^{a}$ \\ a Department of Pharmacology, University of Aarhus, Aarhus, Denmark; ${ }^{b}$ Department of Environmental Chemistry, \\ University of Lodz, Lodz, Poland
}

\section{Key Words}

Remodelling $\cdot$ Hypertension $\cdot$ Spontaneously hypertensive rats $\cdot$ Tissue transglutaminase $\cdot$ Cystamine $\cdot$ Telemetry

\begin{abstract}
Background: Tissue transglutaminase (t-TG) has been implicated in small artery remodelling. The aim of this study was to determine if cystamine, an inhibitor of t-TG, could reduce blood pressure in spontaneously hypertensive rats (SHR) and if so to what extent this is mediated through small arteries. Methods: In vitro inhibition of t-TG, with cystamine, was studied in organ culture and wire myograph setups in small mesenteric arteries obtained from SHR. In vivo treatment with cystamine $(80 \mathrm{mg} / \mathrm{kg} /$ day $)$ or amlodipine $(10 \mathrm{mg} / \mathrm{kg} /$ day) was performed with osmotic pumps in adult SHR, and hemodynamic parameters determined with telemetry. Plasma concentrations of cystamine were determined with a liquid chromatography setup. Small arteries were harvested following administration of cystamine, and structural as well as functional characteristics were determined. Results: SHR small arteries showed inward remodelling following in vitro activation. Administration of cystamine caused attenuation of the inward remodelling induced by activation. In vivo administration of cystamine caused a $9 \pm 2 \mathrm{~mm} \mathrm{Hg}$ reduction in blood pressure, but with no detectable alterations in small artery structure. Conclusion: t-TG is potentially involved in vascular remodelling of SHR small arteries and results support a possible role for t-TG in blood pressure control.
\end{abstract}

Copyright $\odot 2011$ S. Karger AG, Basel

\section{KARGER}

Fax +4161306 1234 E-Mail karger@karger.ch www.karger.com

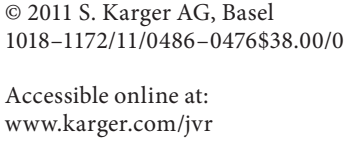

\section{Introduction}

Essential hypertension is associated with alterations of the resistance vessels [1]. Narrowing of the lumen occurs, causing a reduced lumen diameter and increased mediato-lumen ratio, but with no increase in the media crosssectional area. These morphological changes are termed inward eutrophic remodelling and have been demonstrated to be a consequence of rearrangement of the existing extracellular matrix (ECM) in essential hypertension and not by cellular growth as observed in secondary forms of hypertension [2]. Such findings have been reported by numerous studies during the last decades in animal as well as human studies, and it has recently become clear that inward remodelling of the microvasculature causes an increased risk of cardiovascular events [3, 4]. Both low flow conditions [5] and chronic vasoconstriction [6] of resistance arteries are known to induce inward remodelling, but the underlying mechanisms are still to a great extent unknown. Recent findings suggest an important role of the enzyme tissue transglutaminase (t-TG) in rats [7]. t-TG is a bifunctional enzyme with both GTP-hydrolyzing activities and protein cross-linking functions [8]. The enzyme is $\mathrm{Ca}^{2+}$ dependent and ubiquitously expressed within cells and in the ECM [9]. t-TG is known to crosslink ECM proteins, such as fibrinogen and cell surface integrins, via mechanically resistant $N^{\epsilon}(\gamma-$ glutamyl)lysine cross-linkings [10], and it is known to be involved in multiple physiological functions including

Dr. Morten Engholm

Department of Pharmacology, University of Aarhus

University Park 1240

DK-8000 Aarhus C (Denmark)

Tel. +45 8942 1719, E-Mail Morten.engholm.pedersen@farm.au.dk 
cell-cell interaction, cell adhesion, matrix reorganization and wound healing [11]. A role of t-TG in remodelling of resistance vessels is supported by the finding that type 2 Tgase null mice have a delayed development of inward remodelling in response to reduced blood flow, compared to wild-type (WT) mice [12]. Furthermore, small arteries show inward remodelling after exposure to exogenous transglutaminase in vitro [7].

Since inward remodelling of resistance vessels is observed in hypertension, and since t-TG activity depends on pressure [7], there is a possible link between the structural and functional alterations observed in hypertension. Two in vivo studies have been conducted, concerning the role of t-TG in inward remodelling of small arteries, from animals with induced hypertension. In one mouse study the authors induced L-NAME hypertension and found a reduced wall-to-lumen ratio in t-TG knockout mice compared to WT, with no effect on blood pressure [13]. In the second study, authors induced chronic vasoconstriction with phenylephrine and found that cystamine, an organic disulfide with multiple modes of action that includes competitive inhibition of t-TG, attenuates small artery remodelling in normotensive rats [14]. To our knowledge, no studies have determined the role of $\mathrm{t}-\mathrm{TG}$ in animals genetically disposed to hypertension. We have therefore determined whether cystamine administration can cause a reduction in blood pressure of spontaneously hypertensive rats (SHR) and if so to what extent this is mediated through small arteries. In vitro myograph experiments were conducted to assess the role of cystamine on small artery morphology and function, and cystamine was administered in vivo to study unanaesthetized SHR in relation to hemodynamic parameters, obtained with telemetric transmitters.

\section{Materials and Methods}

Experiments were approved by the Animal Ethics Committee and conducted according to Danish legislation. SHR (Charles River Laboratories Inc.) were housed in pairs in the faculty animal facility with a 12-hour light/dark cycle and provided with free access to food and drinking water. Animals were acclimatized for 1 week prior to surgery or euthanization.

\section{In vitro}

Twelve-week-old male SHR were euthanized by cervical dislocation and the mesenteric bed was harvested and immediately immersed in $4^{\circ} \mathrm{C}$ cold physiological saline solution (PSS) of the following composition $\left(10^{-3} \mathrm{M}\right): 119 \mathrm{NaCl}, 4.7 \mathrm{KCl}, 1.18 \mathrm{KH}_{2} \mathrm{PO}_{4}$, $1.17 \mathrm{MgSO}_{4}, 1.5 \mathrm{CaCl}_{2}, 24.9 \mathrm{NaHCO}_{3}, 0.026$ EDTA and 5.5 glucose ( $\mathrm{pH}$ 7.4). Mesenteric second-order branches (diameter ap- proximately $250 \mu \mathrm{m}$ ) were dissected out under clean conditions and carefully cleaned of connective and fat tissue and used for further investigation.

Determination of Structural Changes in Organ Culture

Segments from small mesenteric arteries were cannulated and mounted in an organoid culture setup (Danish Myotechnology, DMT) as described by Bakker et al. [15]. Briefly, arteries were kept in Leibowitch-15 $\left(\mathrm{Gibco}^{\circledR}\right)$ culture medium supplemented with $1 \%$ penicillin/streptomycin at $37^{\circ} \mathrm{C}$ and continuously gassed with $95 \% \mathrm{O}_{2}$ and $5 \% \mathrm{CO}_{2}$. Cannulated vessels were perfused with Leibowitch-15 $+2 \%$ albumin $(\mathrm{pH} 7.4)$ under low-flow conditions (shear stress $<1 \mathrm{dyn} / \mathrm{cm}^{2}$ ) [7]. Images were obtained with a camera placed beneath the vessel using an interface connected to Vediview 1.2 (Photonics Engineering) with integrated Picolo framegrabber. Calibration was performed according to standard procedures and framegrabber adjusted to $19 \%$ gain, 20\% offset and $100 \%$ saturation. Vessel luminal pressure was adjusted to $2 \mathrm{~mm}$ $\mathrm{Hg}$ and maximal dilatation obtained with $10^{-4} \mathrm{M}$ papaverine for $30 \mathrm{~min}$. Passive pressure-diameter relationships from 2 to 120 $\mathrm{mm} \mathrm{Hg}$ were established and vessel internal and external diameter recorded on day 0 . Papaverine was then washed out and the spontaneous tone recorded after $30 \mathrm{~min}$ equilibration at $75 \mathrm{~mm}$ $\mathrm{Hg}$. Arteries were either left untreated or activated with $10^{-8} \mathrm{M}$ ET-1 alone or $10^{-8} \mathrm{M}$ ET-1 in combination with $10^{-4} \mathrm{M}$ cystamine at $50 \mathrm{~mm} \mathrm{Hg}$ for $20 \mathrm{~h}$ and the passive pressure-diameter relationships repeated on day 1 in the presence of $10^{-4} \mathrm{M}$ papaverine. Vessel viability was verified with $10^{-5}$ M 5-HT on day 1 . ET-1, rather than phenylephrine, was used since ET-1 contractions were better maintained than phenylephrine contractions, possibly associated with the common finding that ET-1 is difficult to wash out.

Pharmacological Concentration-Response Experiments

Concentration-response relationships were determined in wire myographs (DMT 410A) as described previously [16]. Briefly, mesenteric second-order branches were mounted as ring preparations on two parallel stainless steel wires $(40 \mu \mathrm{m})$ in myograph chambers containing cold $\left(4^{\circ} \mathrm{C}\right)$ PSS. The solution was gassed with $5 \% \mathrm{CO}_{2}$ and $95 \%$ air, $\mathrm{pH} 7.4$. One wire was connected to a micrometer and the other to a force transducer for isometric measurements of active force development. Active tension was calculated as measured force divided by twice arterial segment length [16]. After mounting, the bath in the myograph was heated to $37^{\circ} \mathrm{C}$ and each vessel was normalized according to standard procedure [16]. Vessel contractility was tested 3 times with $5 \times$ $10^{-6} \mathrm{M}$ noradrenalin prior to experiments and endothelial function was tested by adding $10^{-5} \mathrm{M}$ acetylcholine to the third noradrenalin-mediated contraction. Cumulative phenylephrine concentration-response curves were performed for each artery, and increasing concentrations of cystamine $\left(10^{-5} \mathrm{M}, 10^{-4} \mathrm{M}, 10^{-3} \mathrm{M}\right)$ or amlodipine $\left(10^{-8} \mathrm{M}, 10^{-7} \mathrm{M}, 10^{-6} \mathrm{M}\right)$ were added to the bath and concentration-response curves repeated. A control vessel was taken from each animal and time-controls performed.

\section{In vivo}

Fourteen-week-old male SHR rats $(\mathrm{n}=24,293 \pm 2.5 \mathrm{~g})$ were used to study the role of t-TG in inward remodelling and the reversion of remodelling in relation to blood pressure and artery structure in hypertensive rats. Animals were divided into 3 groups and received treatment with either cystamine $80 \mathrm{mg} / \mathrm{kg} /$ day (Sig- 
ma-Aldrich), amlodipine $10 \mathrm{mg} / \mathrm{kg} /$ day (Pfizer) or $40 \%$ sterile $0.9 \%$ saline $+60 \%$ PEG400 (vehicle) for 3 weeks. At the end of the treatment period, animals were euthanized by cervical dislocation and tissue harvested for further analysis.

\section{Telemetric Measurements of Arterial Pressure}

Animals were anaesthetized with isoflurane (1.5-4\%) and a telemetry transmitter (TA11-PAC40; Data Sciences International) was implanted according to the manufacturer as described by others [17]. Body temperature was kept constant at $37^{\circ} \mathrm{C}$ with a heating plate during surgery. Prior to implantation of transmitters, accuracy was verified with the Dataquest Acquisition program. Under sterile conditions, a skin incision was made in the femoral region and the femoral artery was exposed. A small incision was made in the artery and the transmitter catheter introduced into the aorta through the femoral artery and secured in place with a suture. The transmitter body was implanted intraperitoneally in the abdominal cavity through a midline skin incision and firmly secured to the abdominal wall along the incision with 3-0 (Ethibond Excel) sutures. Skin incisions were closed with 9-mm staples (Autoclips ${ }^{\circledR}$ ) that were removed after healing of incisions. A single injection of benzyl penicillin (Panpharma) was given following surgery as prophylaxis against infection. Postsurgical pain was treated with $0.04 \mathrm{mg}$ buprenorphium (Temge$\operatorname{sic}^{\circledR} 0.3 \mathrm{mg} / \mathrm{ml}$ ). Animals were allowed 8 days to recover from surgery in their normal housing before sampling of 24-hour baseline recordings. Sampling was performed with Dataquest ART ${ }^{\mathrm{TM}}$ Acquisition System (DSI) connected to DSI APR-1 (Ambient Pressure Reference) and data analysis with Dataquest ART Analysis System (DSI). During treatment, 24-hour recordings of systolic and diastolic arterial pressure (sample frequency of 1 every 30 s), heart rate and locomotor activity were performed once every week.

Administration and Formulation of the t-TG Inhibitor

Cystamine and Amlodipine

Following baseline recordings of arterial pressure, treatment was initiated with implantation of osmotic minipumps (Alzet ${ }^{\circledR}$; model 2ML2). One day prior to implantation, pumps were filled with drugs and primed in sterile $0.9 \%$ saline at $37^{\circ} \mathrm{C}$. Subcutaneous implantation of pumps was done in the subscapular region through a small skin incision under anaesthesia with isoflurane. After 12 days of treatment, pumps were renewed by repeating the described procedure. Cystamine was dissolved in sterile $0.9 \%$ saline and amlodipine was dissolved in 60\% PEG400 and $40 \%$ sterile water for pump delivery of drugs. Vehicles were filled with $60 \%$ PEG400 and $40 \%$ sterile water.

\section{Vessel Morphology}

Following 3 weeks of treatment, animals were euthanized and small mesenteric arteries harvested and immediately placed in cold $\left(4^{\circ} \mathrm{C}\right)$ PSS. Three mid-segment second-branch vessels from each animal were selected and dissected by a person blinded to group of treatment. Segments were cannulated and mounted in a pressure myograph (DMT) with the blind-sack method [18]. The inner medium was composed of calcium-free PSS. Investigatorblinded passive pressure-diameter relationships were determined $(0-120 \mathrm{~mm} \mathrm{Hg})$ at $37^{\circ} \mathrm{C}$ after incubation with papaverine $10^{-4} \mathrm{M}$ for $15 \mathrm{~min}$ in a solution of calcium-free PSS in myograph chamber. Mean values for the 3 vessels were used for data analysis [14].
Blood Sample Collection

After 10 days of treatment, blood was collected in microtubes (Sarstedt) containing $1.6 \mathrm{mg}$ EDTA/ml blood, by penetrating the retro-orbital plexus with a glass capillary tube, and immediately placed on ice. Plasma was extracted after centrifugation at 3,000 $\mathrm{rpm}$ for $8 \mathrm{~min}$ at $6^{\circ} \mathrm{C}$ and immediately frozen at $-80^{\circ} \mathrm{C}$.

Determination of Cystamine and Other Thiols in Rat Plasma

Cystamine is the disulphide of cysteamine, but can also exist in plasma as other oxidized forms of cysteamine. We used a liquid chromatography setup to determine total cysteamine in plasma and calculated the concentration of cystamine. The liquid chromatography equipment (Hewlett-Packard; 1100 series system) consisted of a quaternary pump, autosampler, thermostated column compartment, vacuum degasser and diode-array detector and was controlled by HP ChemStation software. Water was purified (Milli-QRG system; Millipore).

Analytical Procedures for Determination of Cysteamine and the Other Thiols

The method for determination of reduced and total thiols is based on derivatization with 2-chloro-1-methylquinolinium tetrafluoroborate (CMQT) [19] to stable 2-S-quinolinium derivatives, and separation and quantitation by ion-pairing reversedphase liquid chromatography [20]. The method is based on the fact that disulfides are converted to their thiol counterparts by reductive cleavage with tris(2-carboxyethyl)phosphine.

Determination of Reduced Thiols, Procedure 1

One hundred microliter of plasma was mixed with $50 \mu \mathrm{l}$ of $0.2 \times 10^{-7} \mathrm{M}$ phosphate buffer (pH 7.6) containing $2 \times 10^{-3} \mathrm{M}$ EDTA, and $10 \mu \mathrm{l}$ of $10^{-2} \mathrm{M}$ CMQT [19]. After 5 min derivatization at room temperature, $15 \mu \mathrm{l}$ of $50 \%$ perchloric acid solution was added, the mixture was vortex mixed and precipitated protein separated by centrifugation for $10 \mathrm{~min}$ at $12,000 \mathrm{~g}$. The supernatant was transferred to a vial, followed by injection $(20 \mu \mathrm{l})$ into the HPLC system.

Determination of Total Thiols, Procedure 2

One hundred microliter of plasma was mixed with $50 \mu \mathrm{l}$ of $0.2 \mathrm{M}$ phosphate buffer ( $\mathrm{pH} 7.6$ ) containing $2 \times 10^{-3} \mathrm{M}$ EDTA, and $10 \mu \mathrm{l}$ of $0.25 \mathrm{M}$ tris $(2$-carboxyethyl)phosphine. After $15 \mathrm{~min}$ reduction at room temperature, $10 \mu \mathrm{l}$ of $0.1 \mathrm{M}$ CMQT were added, vortex mixed and kept at room temperature for $5 \mathrm{~min}$, followed by addition of $15 \mu \mathrm{l}$ of $50 \%$ perchloric acid solution. Precipitated protein was then removed by centrifugation for $10 \mathrm{~min}$ at $12,000 \mathrm{~g}$, supernatant was transferred to a vial and $20 \mu \mathrm{l}$ was injected into the HPLC system.

\section{HPLC Analysis}

Final analytical solutions $(20 \mu \mathrm{l})$ were injected into the Zorbax SB-C18 $(150 \times 4.6 \mathrm{~mm}, 5 \mu \mathrm{m})$ column (Agilent Technologies). For separation of 2-S-quinolinium derivatives of thiols from each other and from reagent excess chromatographic condition described earlier [20] was used. Briefly, the elution profile was as follows: $0-4$ min $12 \% \mathrm{~B}$; $4-7$ min $12-40 \% \mathrm{~B}$; $7-8$ min $40 \% \mathrm{~B} ; 8-10$ min $40-12 \% \mathrm{~B}$. Elution solvent was (A) $5 \times 10^{-2} \mathrm{M}$ trichloroacetic acid buffer $\left(\mathrm{pH} 3,15\right.$ prepared from $5 \times 10^{-2} \mathrm{M}$ TCA and $5 \times$ $10^{-2} \mathrm{M} \mathrm{LiOH}$ ) and (B) acetonitrile. The temperature was $25^{\circ} \mathrm{C}$, the flow rate $1 \mathrm{ml} / \mathrm{min}$ and the detector wavelength $355 \mathrm{~nm}$. Peaks 
identification was based on comparison of retention times and diode-array spectra, taken at real time of analysis, with a corresponding set of data obtained for authentic compounds.

Statistical Analysis

Data are expressed as means \pm SE. Results were analyzed with Student's t test, unless otherwise stated. $\mathrm{p}<0.05$ was considered significant.

\section{Results}

Structural Adaptations during in vitro Organ Culture

Small arteries mounted in organ culture developed spontaneous tone. Artery segments were activated with ET-1 for $20 \mathrm{~h}$ and the passive pressure diameter relationships were determined by comparison of area under curve (AUC) before and after incubation. Resistance arteries from SHR developed a significant reduction in passive lumen diameter after $20 \mathrm{~h}$ of activation with ET-1. AUC was reduced by $7.2 \pm 1.9 \%$ (day 0 vs. day $1, \mathrm{p}<0.05, \mathrm{n}=5$ ), indicating that activation induces inward remodelling in SHR and thereby a reduced lumen diameter for the same level of pressure (fig. 1). Concomitant incubation with cystamine, which among other actions inhibits t-TG, attenuated the inward remodelling induced by activation. In the presence of cystamine, there was no significant change in AUC after activation (1.2 $\pm 0.9 \%$, day 0 vs. day $1, \mathrm{p}>0.05, \mathrm{n}=5$ ) and thereby no significant inward remodelling was induced. This indicates that cystamine attenuates inward remodelling in SHR and supports a role of t-TG in remodelling of SHR small arteries. Control arteries showed no significant change in AUC following $20 \mathrm{~h}$ of culture $(1.6 \pm 0.9 \%$, day 0 vs. day $1, \mathrm{p}>0.05$, $\mathrm{n}=5$ ).

All activated artery segments maintained vasoconstriction during the entire culture period and no change in the initial vasoconstriction induced by ET-1 was observed in the presence of cystamine (fig. 1).

\section{Functional Effects of Cystamine in Small Arteries Obtained from SHR}

The functional effects of cystamine were investigated in the wire myograph. SHR small mesenteric arteries contracted concentration-dependently as response to stimulation with phenylephrine and concentration-response relationships were then determined in the presence of cystamine or amlodipine in increasing concentrations. Cystamine and amlodipine caused concentration-dependent antagonism of phenylephrine-induced vasoconstriction. $10^{-5}$ M cystamine caused a $22.4 \pm 5.9 \%$ reduction in the contractile response to phenylephrine, suggesting a potential vasodilator capacity of cystamine (fig. 2).

Chronic in vivo Administration of Cystamine in SHR

SHR received 3 weeks treatment with cystamine $(80$ $\mathrm{mg} / \mathrm{kg} /$ day) to study if inhibition of $\mathrm{t}-\mathrm{TG}$ could reduce blood pressure and reverse remodelling of small arteries in hypertensive rats. Left ventricular weight was significantly ( $\mathrm{p}<0.05, \mathrm{n}=8$ ) lower in SHR treated with amlodipine than found in SHR receiving treatment with cystamine (table 1). There was a trend for a lower gain of weight in SHR treated with amlodipine than observed in cystamine or vehicle treated animals, but it did not reach statistical significance. Measurements of systemic haemodynamics were performed with telemetry in conscious SHR during administration of cystamine or amlodipine. Chronic treatment with cystamine caused a significant reduction in mean arterial pressure (MAP) of 9 $\mathrm{mm} \mathrm{Hg}$ after 2 weeks treatment (fig. 3; table 2). This drop in MAP was larger than the change in MAP observed in vehicle-treated animals. The blood pressure-lowering effect of cystamine was primarily observed in the diastolic blood pressure, supporting that it could be caused by an increase in the lumen diameter of the small arteries. Amlodipine caused a $22-\mathrm{mm} \mathrm{Hg}$ reduction in MAP.

The experimental procedure caused a $20 \pm 4 \%$ reduction in mean locomotor activity level during the experimental time period; however, treatment had no significant effect on mean activity, either with cystamine or amlodipine ( $\mathrm{p}>0.05,2$-way ANOVA) compared to control. The reduction was thus presumably due to the telemetric transducers and osmotic minipumps.

\section{Determination of Thiols in SHR Plasma}

The plasma concentration of cystamine, together with other thiols, was determined in plasma samples obtained during in vivo administration of cystamine or amlodipine (table 3). Plasma level of cystamine was significantly increased in SHR receiving continuous subcutaneous administration of cystamine in osmotic pumps for 10 days (80 mg/kg/day), confirming appropriate delivery of cystamine. Cystamine could not be detected in SHR receiving vehicle or amlodipine treatment. Plasma level of total-glutathione was significantly higher, while reducedcysteine was significantly lower in SHR receiving continuous subcutaneous administration of amlodipine (10 $\mathrm{mg} / \mathrm{kg} /$ day) than in vehicles. We observed an insignificant trend for a higher level of plasma homocysteine in SHR receiving cystamine and amlodipine than in vehicles (table 3). 




Fig. 1. a Pressure-diameter relationships of maximally dilated small mesenteric arteries from SHR. Activation with $10^{-8}$ M ET-1 induced significant inward remodelling of small artery segments in organ culture $\left({ }^{*} \mathrm{p}<0.05, \mathrm{n}=5\right)$. No significant remodelling was induced when activation was performed with ET-1 in combination with $10^{-4} \mathrm{M}$ cystamine $(\mathrm{p}>0.05, \mathrm{n}=5)$. Control arteries showed no significant change in diameter during culture period $(\mathrm{p}>0.05, \mathrm{n}=5)$. $\mathbf{b}$ Change in AUC from day 0 to day 1 . ET- 1 caused significant inward remodelling which was attenuated by concomitant incubation with cystamine. Data were divided by $120 \mathrm{~mm}$ $\mathrm{Hg}$ to express change in AUC as $\mu \mathrm{m}\left({ }^{* *} \mathrm{p}<0.01,{ }^{* * *} \mathrm{p}<0.001\right.$, one-way ANOVA with post-Tukey test, $\mathrm{n}=5$ ). $\mathbf{c}$ Diameter of vessel segment during organ culture. Passive diameter was obtained with papaverine at $80 \mathrm{~mm} \mathrm{Hg}$. Arteriole segments developed spontaneous tone after removal of papaverine. Segments were either incubated with ET-1 alone or with ET-1 in combination with cystamine. ET-1 induced vasoconstriction that was sustained during organ culture. Passive $(0)=$ Passive diameter on day 0 ; tone $(0)=$ spontaneous tone on day 0 after removal of papaverine; ET-1 $(0)=$ vessel diameter after activation with $10^{-8} \mathrm{M}$ ET-1 on day 0 ; ET-1 (1) = vessel diameter after 20-hour incubation with ET-1.

\section{Structural and Functional Adaptations during Chronic Treatment with Cystamine}

We observed a tendency for an increased vessel diameter, following 3 weeks treatment with cystamine or amlodipine, but it did not reach level of statistical significance (fig. 4; table 4). No significant change in wall to lumen ratio was found, after treatment with cystamine or amlodipine for 3 weeks ( $p>0.05, n=8$, ANOVA). Functional studies of small arteries harvested during followup, showed no difference in maximal tension development to $10 \mu \mathrm{M}$ phenylephrine, between vehicle- $(3.9 \pm$ $0.4 \mathrm{~N} / \mathrm{m})$, cystamine- $(4.3 \pm 0.3 \mathrm{~N} / \mathrm{m})$ or amlodipine- $(3.7$ 
Fig. 2. In vitro wire myograph experiments. Small arteries from SHR $(n=6)$ were mounted for each experiment. Cystamine (CYS) and amlodipine (AM) showed antagonism to phenylephrine-induced concentration-response curves. Data represent mean values \pm SEM. Statistics were performed as change in AUC compared to control $\left({ }^{*} \mathrm{p}<0.05\right.$, ${ }^{* * *} \mathrm{p}<0.001$, repeatedmeasures ANOVA with post-Tukey test).

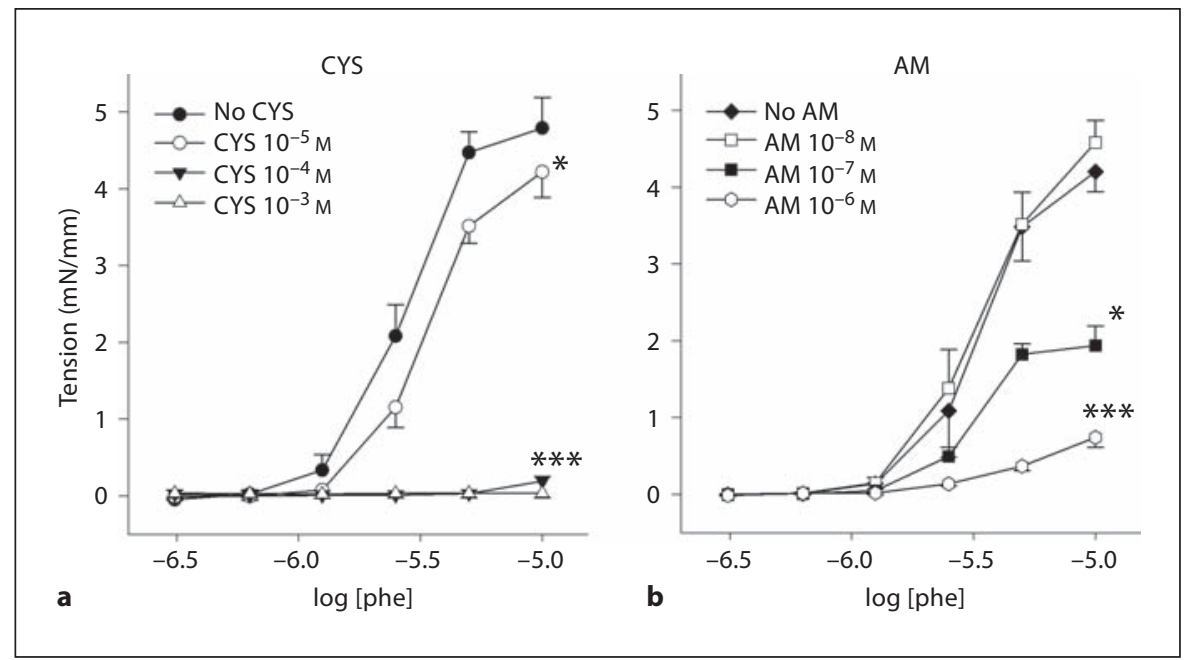

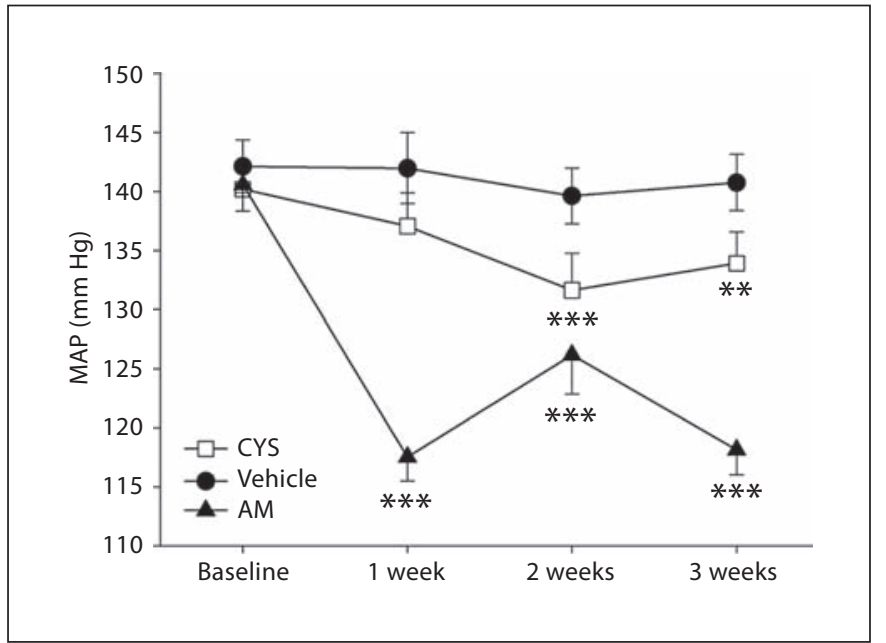

Fig. 3. MAP during 3 weeks treatment with vehicle, cystamine (CYS) or amlodipine (AM) in osmotic minipumps. Cystamine caused a significant reduction in MAP after 2 and 3 weeks administration. Amlodipine also caused significant lowering of MAP. Osmotic minipumps were renewed 2 weeks after implantation, which may explain the fluctuation observed in MAP in animals receiving amlodipine. Details of data are shown in table 2 , which also shows the statistical analysis $\left({ }^{* *} \mathrm{p}<0.01,{ }^{* * *} \mathrm{p}<0.001\right)$.

$\pm 0.4 \mathrm{~N} / \mathrm{m}$ ) treated animals $(\mathrm{p}>0.05, \mathrm{n}=8$, ANOVA). To investigate if chronic administration of cystamine causes interference with the Rho/ROCK pathway and its intracellular functions, wire-mounted small arteries were exposed to the selective inhibitor of Rho-associated kinases Y27632. In cystamine-treated rats, we found (data not shown) that $1 \mu \mathrm{M}$ Y27632 caused a $-35 \pm 8 \%$ reduction
Table 1. Summary of body weight and left ventricular weight

\begin{tabular}{llll}
\hline \multirow{2}{*}{ Group } & \multicolumn{2}{l}{ Body weight, } & \multirow{2}{*}{ LVW, } \\
\cline { 2 - 3 } & baseline & follow-up & \\
\hline Vehicle & $286.6 \pm 6.7$ & $327.4 \pm 5.4$ & $0.97 \pm 0.03$ \\
Cystamine & $281.3 \pm 7.3$ & $325.6 \pm 3.3$ & $1.02 \pm 0.02$ \\
Amlodipine & $277.6 \pm 1.7$ & $305.3 \pm 4.9$ & $0.91 \pm 0.02^{*}$ \\
\hline
\end{tabular}

Data are means \pm SEM. Twenty-two SHR received treatment with vehicle, cystamine or amlodipine. LVW = Left ventricular weight. ${ }^{*} \mathrm{p}<0.05$, amlodipine vs. cystamine, ANOVA.

in contractile response to phenylephrine, which was not significantly different from the change observed with vehicle or amlodipine $(-21 \pm 16,-40 \pm 8 \%, \mathrm{p}>0.05, \mathrm{n}=$ 8, ANOVA). Taken together the data indicate that no morphological or functional changes are induced in SHR small arteries after 3 weeks treatment with cystamine or amlodipine.

\section{Discussion}

The primary findings in this paper were that in vitro activation of resistance arteries induces inward remodelling of SHR small arteries and that cystamine (a competitive inhibitor of t-TG) attenuates inward remodelling in hypertensive rats in vitro. We also found that 3-week in vivo administration of cystamine causes modest reduc- 
Table 2. Cardiovascular responses to chronic administration of cystamine or amlodipine in SHR

\begin{tabular}{|c|c|c|c|c|c|c|c|c|c|c|}
\hline & \multirow{2}{*}{$\begin{array}{l}\text { Baseline } \\
(\mathrm{n}=22)\end{array}$} & \multicolumn{3}{|c|}{ Vehicle $(\mathrm{n}=7)$} & \multicolumn{3}{|c|}{ Cystamine $(\mathrm{n}=7)$} & \multicolumn{3}{|c|}{ Amlodipine $(\mathrm{n}=8)$} \\
\hline & & 1 week & 2 weeks & 3 weeks & 1 week & 2 weeks & 3 weeks & 1 week & 2 weeks & 3 weeks \\
\hline Heart rate, bpm & $331 \pm 3$ & $335 \pm 4^{*}$ & $328 \pm 3$ & $327 \pm 5$ & $352 \pm 5$ & $353 \pm 5^{*}$ & $331 \pm 3$ & $340 \pm 5^{* *}$ & $340 \pm 3^{* * *}$ & $329 \pm 3$ \\
\hline MAP, mm Hg & $141 \pm 1$ & $142 \pm 3$ & $140 \pm 2$ & $141 \pm 2$ & $137 \pm 3$ & $132 \pm 3^{* * *}$ & $134 \pm 3^{* *}$ & $118 \pm 2^{* * *}$ & $126 \pm 3^{* * *}$ & $118 \pm 2^{* * *}$ \\
\hline Systolic BP, mm Hg & $168 \pm 1$ & $171 \pm 3$ & $170 \pm 2$ & $171 \pm 2$ & $164 \pm 3$ & $160 \pm 3^{*}$ & $161 \pm 4$ & $145 \pm 2^{* * *}$ & $154 \pm 4^{* * *}$ & $145 \pm 3^{* * *}$ \\
\hline Diastolic BP, mm Hg & $113 \pm 1$ & $113 \pm 3$ & $110 \pm 2$ & $111 \pm 3$ & $111 \pm 3$ & $104 \pm 3^{* * *}$ & $108 \pm 3^{* *}$ & $92 \pm 2^{* * *}$ & $100 \pm 3^{* * *}$ & $93 \pm 2^{* * *}$ \\
\hline Pulse pressure, $\mathrm{mm} \mathrm{Hg}$ & $55 \pm 1$ & $59 \pm 1$ & $59 \pm 1^{*}$ & $60 \pm 2^{*}$ & $53 \pm 3$ & $56 \pm 2$ & $52 \pm 4$ & $53 \pm 1^{*}$ & $54 \pm 2$ & $52 \pm 3^{*}$ \\
\hline
\end{tabular}

Data are means \pm SEM obtained with telemetry (DSI) in SHR that underwent chronic administration with either vehicle, cystamine or amlodipine. Data analyzed by two-way ANOVA. In all cases there was significant interaction and data were then compared to baseline using Bonferroni post-test. $\mathrm{BP}=$ Blood pressure.

${ }^{*} \mathrm{p}<0.05,{ }^{* *} \mathrm{p}<0.01,{ }^{* * *} \mathrm{p}<0.001$.

Table 3. SHR plasma thiols during treatment with cystamine and amlodipine

\begin{tabular}{llll}
\hline Thiols, nmol/ml & \multicolumn{3}{l}{ Group } \\
\cline { 2 - 4 } & $\begin{array}{l}\text { vehicle } \\
(\mathrm{n}=7)\end{array}$ & $\begin{array}{l}\text { cystamine } \\
(\mathrm{n}=7)\end{array}$ & $\begin{array}{l}\text { amlodipine } \\
(\mathrm{n}=8)\end{array}$ \\
\hline Cystamine & $\mathrm{n} . \mathrm{m}$. & $2.47 \pm 0.36^{* * *}$ & $\mathrm{n} . \mathrm{m}$. \\
Total glutathione & $31.14 \pm 1.85$ & $32.78 \pm 1.50$ & $37.41 \pm 1.19^{*}$ \\
Total homocysteine & $2.36 \pm 0.23$ & $2.94 \pm 0.18$ & $3.19 \pm 0.32$ \\
Total cysteine & $232.7 \pm 21.0$ & $214.4 \pm 32.9$ & $273.1 \pm 32.2$ \\
Reduced cysteine & $21.91 \pm 2.26$ & $19.48 \pm 1.65$ & $12.31 \pm 1.96^{* *}$ \\
\hline
\end{tabular}

Data are means \pm SEM obtained in 22 SHR after 10 days of treatment with cystamine $(80 \mathrm{mg} / \mathrm{kg} /$ day $)$ or amlodipine $(10 \mathrm{mg} / \mathrm{kg} /$ day $)$.

n.m. = Not measurable. ${ }^{*} \mathrm{p}<0.05,{ }^{* *} \mathrm{p}<0.01,{ }^{* *} \mathrm{p}<0.001$ vs. vehicle by ANOVA.

tion in MAP but does not cause detectable structural or functional changes in small arteries.

We used an organ culture setup to demonstrate that inhibition of t-TG attenuates inward remodelling in SHR. Certain limitations exist with this method since vessel segments are not in their habitual environment but mounted in vitro and kept in organ culture medium, which may influence their functional and morphological characteristics. However, vessels maintained viability during the culture period as previously shown [21]. Furthermore, our finding that induction of inward remodelling occurs as a response to long-term vasoconstriction in SHR is consistent with previous findings in Wistar rats [6]. t-TG activity has been shown to be dependent on pressure and recent findings demonstrate that ET-1 increases t-TG mRNA and protein expression in a concentration-dependent manner
Table 4. Normalized small artery structure from SHR treated with cystamine or amlodipine

\begin{tabular}{lccc}
\hline & Vehicle & Cystamine & Amlodipine \\
\hline Lumen diameter, $\mu \mathrm{m}$ & $253.7 \pm 4.2$ & $279.2 \pm 16.1$ & $269.5 \pm 9.3$ \\
Wall thickness, $\mu \mathrm{m}$ & $72.58 \pm 2.6$ & $72.56 \pm 2.4$ & $67.64 \pm 3.3$ \\
W:L ratio, \% & $14.40 \pm 0.59$ & $14.14 \pm 0.59$ & $13.19 \pm 1.0$ \\
WCSA, $\mu \mathrm{m}^{2}$ & $33,213 \pm 1,370$ & $33,633 \pm 1,339$ & $32,132 \pm 1,370$
\end{tabular}

Data are means \pm SEM. Small mesenteric arteries from 24 SHR $(\mathrm{n}=8)$ were mounted in pressure myographs and normalized to 60 $\mathrm{mm} \mathrm{Hg}$. No significant differences were found in small artery structure between groups by ANOVA; however, a trend for increased lumen diameter following treatment with amlodipine or cystamine was observed. $\mathrm{WCSA}=\mathrm{Wall}$ cross-sectional area; $\mathrm{W}: \mathrm{L}$ ratio $=$ wall to lumen ratio.

via the $\mathrm{ET}_{\mathrm{A}}$ receptor in rat cardiomyocytes [7,22], suggesting two potential mechanisms for the induction of inward remodelling by ET-1. Increased tone in small artery smooth muscle cells causes activation of t-TG, which facilitates rearrangement and formation of cross-linking in the ECM, around a narrowed lumen. Addition of selective t-TG inhibitors, including cystamine, attenuates the development of inward remodelling by blocking of t-TG's active site and thereby blocking of the cross-link formation in the ECM [7]. This was supported by Eftekhari et al. [14] who showed that in vivo activation of resistance arteries induces inward remodelling in normotensive rats, and that this could be inhibited by inhibition with cystamine.

The action of cystamine ( $\beta$-mercaptoethanolamine, MEA, disulfide) is thought to be through its reduction to MEA within the cells. MEA acts as a t-TG substrate and 


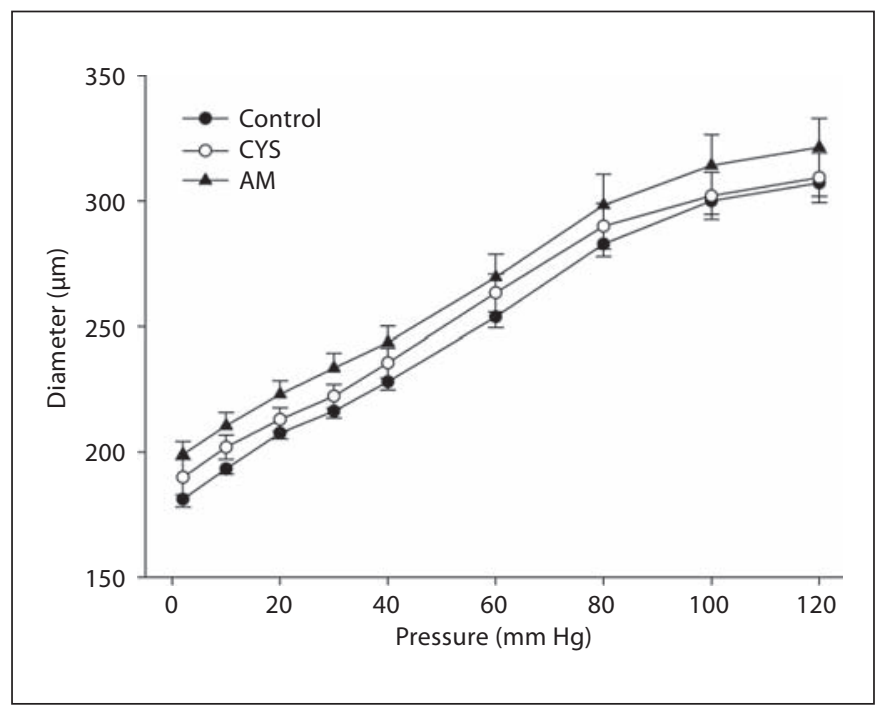

Fig. 4. Passive pressure-diameter relationships of small mesenteric arteries harvested from SHR receiving treatment with either vehicle, cystamine (CYS, $80 \mathrm{mg} / \mathrm{kg} /$ day) or amlodipine (AM, 10 $\mathrm{mg} / \mathrm{kg} /$ day) for 3 weeks. No significant morphological alterations were induced by cystamine or amlodipine $(n=7, p>0.05)$.

results in the formation of $\mathrm{N}^{\epsilon}(\gamma$-glutamyl)-MEA bonds and thereby competes with the generation of other TGcatalyzed reactions, such as cross-linking of ECM components [23]. Introduction of cystamine (oxidized form of MEA) into the system generates change of the redox status towards more oxidative environment leading to the decrease in reduced cysteine concentration (table 3). Oxidation environment in turn is likely to promote inactivation of transglutaminase. This finding is consistent with the recent results of investigations of other researchers on the influence of oxidation on the amount of active t-TG [24]. Likewise, NO suppresses activity and increases $S$-nitrosylation of t-TG in cellular models [25]. t-TG activity and the level of TG-specific bonds [ $\mathrm{N}^{\epsilon}(\gamma$-glutamyl)lysine] is increased in the cerebrospinal fluid of patients with Huntington's disease [26], and in vivo administration of cystamine in a transgenic Huntington's disease mouse model has been demonstrated to reduce t-TG activity as well as the level of TG-specific bindings, thereby decreasing symptoms and prolonging survival in mice with Huntington's disease $[27,28]$. In agreement with previous findings, this supports the suggestion that administration of cystamine is associated with competitive inhibition of t-TG. It has previously been shown that intraperitoneal administration of cystamine attenuates inward remodelling induced by low-flow conditions, and cystamine has been demonstrated to attenuate phenylephrine-induced inward remodelling in rats, independent of blood pressure [14]. Moreover, a recent study shows that cystamine causes significant attenuation of inward remodelling in pulmonary arteries from rats with chronic hypoxia-induced pulmonary hypertension, with no change in pulmonary arterial pressure [22]. This finding suggests that the role of $\mathrm{t}$-TG in remodelling is not restricted to systemic hypertension but also involves pulmonary hypertension.

We aimed to study if reduction in vascular smooth muscle t-TG activity, following chronic administration of cystamine, could reduce blood pressure. We performed measurements of haemodynamics in conscious SHR with telemetry, which is currently considered the 'gold standard' of hemodynamic measurements in laboratory animals, and we observed significant reduction in MAP after treatment with cystamine. Pistea et al. [13] found no difference in blood pressure between t-TG knockout mice and WT with L-NAME hypertension, despite a more pronounced development of inward remodelling in WT, indicating that in that model blood pressure is unaffected by the alterations mediated by t-TG in the vessel wall. We used a cystamine concentration of $80 \mathrm{mg} / \mathrm{kg} /$ day which was higher than that used in the previously mentioned studies of resistance artery structure (10-40 mg/kg/day), but significantly lower than the doses used in neurological research of Huntington's disease $(100-400 \mathrm{mg} / \mathrm{kg} /$ day) [29]. We found mean plasma cystamine concentration to be about $2.5 \mathrm{nmol} / \mathrm{ml}$ (table 2), and more research is needed to answer whether the reduction in MAP caused by cystamine was due to attenuation of t-TG cross-linking activity or by its vasodilator activity (fig. 2), possibly by interference with $\mathrm{t}-\mathrm{TG}$ 's role as a $\mathrm{G}$ protein in transmembrane signalling [30].

The observed reduction in MAP with cystamine was not associated with change in vascular structure. The lack of improvement in the vascular structure may be because longer treatment is needed or because it was too small to detect. Furthermore, the cross-links mediated by t-TG in ECM have high mechanical and chemical stability which would tend to prevent remodelling, as shown previously in organ culture [14]. The dose of amlodipine used in the study $(10 \mathrm{mg} / \mathrm{kg} /$ day $)$ did not cause significant reversion of remodelling either, despite its vasodilator effect and previously demonstrated ability to regress structural remodelling in small arteries from SHR [31]; however, there the treatment period was longer (12 weeks) and the dose higher $(20 \mathrm{mg} / \mathrm{kg} /$ day $)$.

In conclusion, to the extent that cystamine is an inhibitor of $\mathrm{t}-\mathrm{TG}$, our results support a role of $\mathrm{t}-\mathrm{TG}$ in vas- 
cular remodelling since cystamine attenuated ET-1-induced remodelling in SHR. Furthermore, mean arterial pressure was slightly reduced following administration of cystamine, but without functional or structural changes in small arteries.

\section{Acknowledgements}

This project was supported by the Danish Medical Research Council. We thank Henriette Johansson for excellent technical assistance.

\section{References}

-1 Aalkjaer C, Heagerty AM, Petersen KK, 12 Bakker EN, Pistea A, Spaan JA, Rolf T, de Swales JD, Mulvany MJ: Evidence for increased media thickness, increased neuronal amine uptake, and depressed excitationcontraction coupling in isolated resistance vessels from essential hypertensives. Circ Res 1987;61:181-186.

$\checkmark 2$ Korsgaard N, Aalkjaer C, Heagerty AM, Izzard AS, Mulvany MJ: Histology of subcutaneous small arteries from patients with essential hypertension. Hypertension 1993;22: 523-526.

-3 Mathiassen ON, Buus NH, Sihm I, Thybo NK, Morn B, Schroeder AP, Thygesen K, Aalkjaer C, Lederballe O, Mulvany MJ, Christensen KL: Small artery structure is an independent predictor of cardiovascular events in essential hypertension. J Hypertens 2007;25:1021-1026.

4 Rizzoni D, Porteri E, Boari GE, De CC, Sleiman I, Muiesan ML, Castellano M, Miclini M, Agabiti-Rosei E: Prognostic significance of small-artery structure in hypertension. Circulation 2003;108:2230-2235.

$\checkmark 5$ Buus CL, Pourageaud F, Fazzi GE, Janssen G, Mulvany MJ, De Mey JG: Smooth muscle cell changes during flow-related remodeling of rat mesenteric resistance arteries. Circ Res 2001;89:180-186.

-6 Bakker EN, van Der Meulen ET, van den Berg BM, Everts V, Spaan JA, VanBavel E: Inward remodeling follows chronic vasoconstriction in isolated resistance arteries. Vasc Res 2002;39:12-20.

$\checkmark 7$ Bakker EN, Buus CL, Spaan JA, Perree J, Ganga A, Rolf TM, Sorop O, Bramsen LH, Mulvany MJ, VanBavel E: Small artery remodeling depends on tissue-type transglutaminase. Circ Res 2005;96:119-126.

$\checkmark 8$ Lee KN, Birckbichler PJ, Patterson MK Jr: GTP hydrolysis by guinea pig liver transglutaminase. Biochem Biophys Res Commun 1989;162:1370-1375.

9 Akimov SS, Krylov D, Fleischman LF, Belkin AM: Tissue transglutaminase is an integrinbinding adhesion coreceptor for fibronectin. J Cell Biol 2000;148:825-838.

-10 Martinez J, Chalupowicz DG, Roush RK, Sheth A, Barsigian C: Transglutaminasemediated processing of fibronectin by endothelial cell monolayers. Biochemistry 1994; 33:2538-2545.

11 Lorand L, Graham RM: Transglutaminases: crosslinking enzymes with pleiotropic functions. Nat Rev Mol Cell Biol 2003;4:140-156.
Vries CJ, van RN, Candi E, VanBavel E: Flow-dependent remodeling of small arteries in mice deficient for tissue-type transglutaminase: possible compensation by macrophage-derived factor XIII. Circ Res 2006;99: 86-92.

13 Pistea A, Bakker EN, Spaan JA, Hardeman MR, van RN, VanBavel E: Small artery remodeling and erythrocyte deformability in L-NAME-induced hypertension: role of transglutaminases. J Vasc Res 2008;45:1018.

14 Eftekhari A, Rahman A, Schaebel LH, Chen $\mathrm{H}$, Rasmussen CV, Aalkjaer C, Buus CL, Mulvany MJ: Chronic cystamine treatment inhibits small artery remodelling in rats. J Vasc Res 2007;44:471-482.

15 Bakker EN, van Der Meulen ET, Spaan JA, VanBavel E: Organoid culture of cannulated rat resistance arteries: effect of serum factors on vasoactivity and remodeling. Am J Physiol Heart Circ Physiol 2000;278:H1233H1240.

16 Mulvany MJ, Halpern W: Contractile properties of small arterial resistance vessels in spontaneously hypertensive and normotensive rats. Circ Res 1977;41:19-26.

17 Balakrishnan S, McNeill JR: Cardiac output mediates the antihypertensive effect of vasopressin in spontaneous hypertension. Am J Physiol 1996;271:H1728-H1733.

-18 McCarron JG, Quayle JM, Halpern W, Nelson MT: Cromakalim and pinacidil dilate small mesenteric arteries but not small cerebral arteries. Am J Physiol 1991;261:H287H291.

19 Bald E, Glowacki R: 2-Chloro-1-methylquinolinium tetrafluoroborate as an effective and thiol specific UV-tagging reagent for liquid chromatography. J Liq Chromatogr Relat Technol 2001;24:1323-1339.

20 Kusmierek K, Glowacki R, Bald E: Determination of total cysteamine in human plasma in the form of its 2-S-quinolinium derivative by high performance liquid chromatography. Anal Bioanal Chem 2005;382:231-233.

21 Adner M, Geary GG, Edvinsson L: Appearance of contractile endothelin-B receptors in rat mesenteric arterial segments following organ culture. Acta Physiol Scand 1998;163: 121-129.

22 Li X, Wei XL, Meng LL, Chi MG, Yan JQ, Ma XY, Jia YS, Liang L, Yan HT, Zheng JQ: Involvement of tissue transglutaminase in en- dothelin 1-induced hypertrophy in cultured neonatal rat cardiomyocytes. Hypertension 2009;54:839-844.

23 Jeitner TM, Delikatny EJ, Ahlqvist J, Capper $\mathrm{H}$, Cooper AJ: Mechanism for the inhibition of transglutaminase 2 by cystamine. Biochem Pharmacol 2005;69:961-970.

24 Stamnaes J, Pinkas DM, Fleckenstein B, Khosla C, Sollid LM: Redox regulation of transglutaminase 2 activity. J Biol Chem 2010;285:25402-25409.

25 Santhanam L, Tuday EC, Webb AK, Dowzicky P, Kim JH, Oh YJ, Sikka G, Kuo M, Halushka MK, Macgregor AM, Dunn J, Gutbrod S, Yin D, Shoukas A, Nyhan D, Flavahan NA, Belkin AM, Berkowitz DE: Decreased S-nitrosylation of tissue transglutaminase contributes to age-related increases in vascular stiffness. Circ Res 2010;107:117125.

26 Jeitner TM, Bogdanov MB, Matson WR, Daikhin Y, Yudkoff M, Folk JE, Steinman L, Browne SE, Beal MF, Blass JP, Cooper AJ: $\mathrm{N} \varepsilon$-( $\gamma$-L-glutamyl)-L-lysine (GGEL) is increased in cerebrospinal fluid of patients with Huntington's disease. J Neurochem 2001;79:1109-1112.

-27 Dedeoglu A, Kubilus JK, Jeitner TM, Matson SA, Bogdanov M, Kowall NW, Matson WR, Cooper AJ, Ratan RR, Beal MF, Hersch SM, Ferrante RJ: Therapeutic effects of cystamine in a murine model of Huntington's disease. J Neurosci 2002;22:8942-8950.

28 Karpuj MV, Becher MW, Springer JE, Chabas D, Youssef S, Pedotti R, Mitchell D, Steinman L: Prolonged survival and decreased abnormal movements in transgenic model of Huntington disease, with administration of the transglutaminase inhibitor cystamine. Nat Med 2002;8:143-149.

29 Van Raamsdonk JM, Pearson J, Bailey CD, Rogers DA, Johnson GV, Hayden MR, Leavitt BR: Cystamine treatment is neuroprotective in the YAC128 mouse model of Huntington disease. J Neurochem 2005;95:210-220.

30 Im MJ, Russell MA, Feng JF: Transglutaminase II: a new class of GTP-binding protein with new biological functions. Cell Signal 1997;9:477-482.

31 Sharifi AM, Li JS, Endemann D, Schiffrin EL: Effects of enalapril and amlodipine on small-artery structure and composition, and on endothelial dysfunction in spontaneously hypertensive rats. J Hypertens 1998;16:457466. 